\title{
Diversity among Modern Tomato Genotypes at Different Levels in Fresh-Market Breeding
}

\author{
Krishna Bhattarai, ${ }^{1}$ Sadikshya Sharma, ${ }^{2}$ and Dilip R. Panthee $\mathbb{D}^{1}$ \\ ${ }^{1}$ Department of Horticultural Science, North Carolina State University, Mountain Horticultural Crops Research and Extension Center, \\ Mills River, NC 28759, USA \\ ${ }^{2}$ Department of Environmental Horticulture, University of Florida, 2550 Hull Rd, Gainesville, FL 32611, USA
}

Correspondence should be addressed to Dilip R. Panthee; dilip_panthee@ncsu.edu

Received 13 February 2018; Accepted 19 March 2018; Published 22 May 2018

Academic Editor: Allen Barker

Copyright ( 2018 Krishna Bhattarai et al. This is an open access article distributed under the Creative Commons Attribution License, which permits unrestricted use, distribution, and reproduction in any medium, provided the original work is properly cited.

\begin{abstract}
Cultivated tomato has been in existence for about 400 years and breeding activities have been conducted for only eight decades. However, more than 10,000 tomato cultivars have already been developed. Ninety-one tomato genotypes were characterized for twenty-one morphological traits using developmental, vegetative, and fruit traits. Correlation, principal component, and cluster analysis between the traits were carried out. Higher correlations between fruit traits including fruit shape, fruit size, and fruit types were observed. These correlations indicate that specific fruit types require specific traits like branched inflorescence and a greater number of fruits per inflorescence are beneficial only for smaller fruit sizes like cherry and grape tomatoes. Contrastingly, traits like determinate growth habit and fruit maturity are preferred in all fruit types of tomato for better cultivation practices and longer production duration and hence showed lower correlations. Principal component analysis clustered tomato genotypes into three main clusters with multiple subgroups. Similar tomato genotypes were placed into one or more clusters confirming the results from correlation analysis. Involvement of private breeding programs in cultivar development has increased the competition on introgression of novel and desired traits across new cultivars. Understanding the diversity present in modern cultivars and potential traits identification in related wild species can enhance tomato diversity and improve quality and production.
\end{abstract}

\section{Introduction}

Tomato is one of the most important vegetables produced all over the world. It belongs to the diverse Solanaceae family along with potato, pepper from the South American origin, and eggplant from Asia. Tomato breeding in the modern era has focused on increased production and adaptation to different consumption need. With Latin American origin, the domesticated tomato was cultivated in South America with selection for edible fruits, attractive red color, and increased fruit size as compared to the wild tomato. There have been several bottlenecks over the ages leading to severe reduction in its genetic diversity during domestication, introduction to Europe, and introduction in the US [1]. Due to the broad adaptation of tomato from Alaska in summer to tropical conditions, there have been adaptive and morphological variations. However, introgression of highly desirable characteristics and higher selection pressure to select those traits in tomato population has decreased the genetic diversity [2]. Phenotypic characteristics have been used to study genetic differences and for genetic diversity analysis and cultivar development [3-6]. Assessment of diversity in commercial cultivars provides the status of a crop in relation to its wild and domesticated relatives and assists in creating a breeding scheme to bring in the lost alleles due to extreme selection and bottlenecks during domestication or introduction [7]. In the absence of genetic variation, breeding efforts in crops remain without any gain [8]. This may lead to severe crop failure with the onset of new biotic or abiotic stress. Most of the disease resistant genes in modern varieties are not only the result of selection from these varieties but also originated from the wild species [9]. 
In this study, we characterized ninety-one tomato genotypes for twenty-one phenotypic traits based on tomato descriptors developed by International Plant Genetic Resources Institute [10] and additional methods with some modifications. Tomato genotypes that are actively used in developing modern varieties by different breeding programs are studied to understand their morphological characteristics and develop a scenario on the level of diversity available among these lines that develop into or give rise to new cultivars in the near future.

\section{Materials and Methods}

2.1. Plant Materials. Ninety-one tomato genotypes from ten public and private breeding programs including breeding lines, hybrids, and advanced lines were selected and studied in the breeding programs (Table 1). These genotypes were sown in flatbed metal trays in a soilless seeding mixture $(2: 2: 1 \mathrm{v} / \mathrm{v} / \mathrm{v}$ peat moss: pine bark: vermiculite) with macroand micronutrients (Van Wingerden International Inc., Mills River, NC). The germinated seedlings were transplanted to 72-cell flat trays after ten days of sowing and were grown for four weeks before they were transplanted in the field. These plants were planted in the field at Mountain Horticultural Crops Research and Extension Center, Mills River, North Carolina, with complete randomized block design with two blocks. Six plants per genotype were planted in each block with $45 \mathrm{~cm}$ space between individuals and $150 \mathrm{~cm}$ between rows. Management practices for fertilization, diseases, and insects control and irrigation were applied according to standard recommendations for tomato production in North Carolina [11].

2.2. Data Collection. Vegetative and reproductive traits that are related to tomato production and quality were measured using quantitative or a rated scale. Data for each plot were collected by averaging the performance of six individuals present in each plot. All the traits measured and the scale are illustrated in Table 2. Quantitative traits like seeding and plant heights were measured using a measuring tape, chlorophyll content was measured by SPAD 502 plus chlorophyll meter (Spectrum Technologies, Aurora, IL, USA), and fruits per inflorescence were measured by counting number of completely developed fruits in a cluster manually. Rating for bacterial spot disease was done by using Horsfall and Barrett scale and late blight severity was rated by using percentage rating converted to a scale of one to five where one indicated the least late blight severity. Both bacterial spot and late blight diseases were not inoculated artificially but developed naturally despite regular application of recommended control measures. Therefore, leaf spot and late blight diseases severities were rated at the fruit harvest to assess the genotypic performance of each tomato line. Morphological foliar and fruit traits were rated using the scale recommended on tomato descriptor developed by International Plant Genetic Resources Institute [10]. There were 11 fruits related traits and four vegetative traits that were rated using tomato descriptor scales.
TABLE 1: List of fresh market tomato genotypes including breeding lines, advanced lines, and selections and hybrids that are being used or tested in tomato breeding programs for the development of new varieties.

\begin{tabular}{|c|c|c|}
\hline Genotype & Company $^{\alpha}$ & Type $^{\beta}$ \\
\hline Carolina Gold & NCSU & HY \\
\hline Cherokee & NCSU & $\mathrm{BL}$ \\
\hline Fletcher & NCSU & HY \\
\hline Monte Verde & NCSU & $\mathrm{BL}$ \\
\hline Mountain Belle & NCSU & HY \\
\hline Mountain Fresh & NCSU & HY \\
\hline Mountain Glory & NCSU & HY \\
\hline Mountain Gold & NCSU & $\mathrm{BL}$ \\
\hline Mountain Magic & NCSU & HY \\
\hline Mountain Majesty & NCSU & HY \\
\hline Mountain Merit & NCSU & HY \\
\hline Mountain Pride & NCSU & HY \\
\hline Mountain Spring & NCSU & HY \\
\hline Mountain Supreme & NCSU & HY \\
\hline NC1 Grape & NCSU & $\mathrm{BL}$ \\
\hline NC109 & NCSU & $\mathrm{BL}$ \\
\hline $\mathrm{NC1C}$ & NCSU & $\mathrm{BL}$ \\
\hline NC 714 & NCSU & $\mathrm{BL}$ \\
\hline NC1CELBR & NCSU & $\mathrm{BL}$ \\
\hline NC1CS & NCSU & $\mathrm{BL}$ \\
\hline NC1rinEC & NCSU & $\mathrm{BL}$ \\
\hline $\mathrm{NClY}$ & NCSU & $\mathrm{BL}$ \\
\hline NC2 Grape & NCSU & $\mathrm{BL}$ \\
\hline NC25P & NCSU & $\mathrm{BL}$ \\
\hline $\mathrm{NC} 2 \mathrm{C}$ & NCSU & $\mathrm{BL}$ \\
\hline NC2CELBR & NCSU & $\mathrm{BL}$ \\
\hline NC2rinEC & NCSU & $\mathrm{BL}$ \\
\hline NC3 Grape & NCSU & $\mathrm{BL}$ \\
\hline NC30P & NCSU & $\mathrm{BL}$ \\
\hline NC50-7 & NCSU & $\mathrm{BL}$ \\
\hline NC8276 & $\mathrm{NCSU}$ & $\mathrm{BL}$ \\
\hline NC8288 & NCSU & $\mathrm{BL}$ \\
\hline NC84173 & NCSU & $\mathrm{BL}$ \\
\hline NC946 & NCSU & $\mathrm{BL}$ \\
\hline NCEBR1 & NCSU & $\mathrm{BL}$ \\
\hline NCEBR2 & NCSU & $\mathrm{BL}$ \\
\hline NCEBR3 & NCSU & $\mathrm{BL}$ \\
\hline NCEBR5 & NCSU & $\mathrm{BL}$ \\
\hline NCEBR6 & NCSU & $\mathrm{BL}$ \\
\hline NCEBR7 & NCSU & $\mathrm{BL}$ \\
\hline NCEBR8 & NCSU & $\mathrm{BL}$ \\
\hline NCHS1 & NCSU & $\mathrm{BL}$ \\
\hline Piedmont & $\mathrm{NCSU}$ & $\mathrm{BL}$ \\
\hline Plum Crimson & NCSU & HY \\
\hline Plum Dandy & NCSU & HY \\
\hline Plum Regal & NCSU & $\mathrm{HY}$ \\
\hline Smarty & NCSU & $\mathrm{HY}$ \\
\hline Summit & NCSU & $\mathrm{BL}$ \\
\hline
\end{tabular}


TABle 1: Continued.

\begin{tabular}{|c|c|c|}
\hline Genotype & Company $^{\alpha}$ & Type $^{\beta}$ \\
\hline Sun Leaper & NCSU & HY \\
\hline Mountain Vineyard & NCSU & HY \\
\hline Mountain Honey & NCSU & $\mathrm{HY}$ \\
\hline Mountain Rouge & NCSU & HY \\
\hline NC 161L & NCSU & $\mathrm{BL}$ \\
\hline NC 4Grape & $\mathrm{NCSU}$ & $\mathrm{BL}$ \\
\hline NC 5Grape & NCSU & $\mathrm{BL}$ \\
\hline UG 1104113 & UG & HY \\
\hline UG 1155013 & UG & HY \\
\hline XTM0017 & SSA & HY \\
\hline XTM7262 & SSA & HY \\
\hline PSGH-13-16 & PSU & HY \\
\hline PSGH-13-33 & PSU & HY \\
\hline PSFH-13-19 & PSU & HY \\
\hline PSFH-13-47 & PSU & $\mathrm{HY}$ \\
\hline Iron Lady & HMOS & HY \\
\hline Ridge Runner & SYN & HY \\
\hline Monticello & SYN & $\mathrm{HY}$ \\
\hline Brickyard & SYN & $\mathrm{HY}$ \\
\hline Summerpick & SYN & HY \\
\hline Richmond & SYN & HY \\
\hline NC33EB1 x CUTR 1st Gen CUTR & $\mathrm{CU}$ & HY \\
\hline NC33EB1 x CUTR 2nd Gen 124116-4 & $\mathrm{CU}$ & HY \\
\hline VFT Vendor x CUTR 2nd Gen 124116-4 & $\mathrm{CU}$ & $\mathrm{HY}$ \\
\hline NC132S x PAU351-Y & NCL & HY \\
\hline NC132S x PAU332 & NCL & HY \\
\hline PAU332 x NC2rinEC & NCL & HY \\
\hline YCBT-1 x NC2rinEC & NCL & HY \\
\hline 335 x NC132S & NCL & HY \\
\hline $\mathrm{NC132S} \times \mathrm{C} 23-3$ & NCL & HY \\
\hline 335 x NC2CELBR & NCL & HY \\
\hline NC2CELBR x C23-3 & NCL & HY \\
\hline YCBT-1 xN C132S & NCL & HY \\
\hline NC2CELBR x PAU332 & NCL & HY \\
\hline NC2CELBR x PAU351-Y & NCL & HY \\
\hline $141 \mathrm{G}$ & NCSU & $\mathrm{BL}$ \\
\hline $143 \mathrm{G}$ & NCSU & $\mathrm{BL}$ \\
\hline $145 \mathrm{G}$ & NCSU & $\mathrm{BL}$ \\
\hline $147 \mathrm{G}$ & $\mathrm{NCSU}$ & $\mathrm{BL}$ \\
\hline $148 \mathrm{G}$ & NCSU & $\mathrm{BL}$ \\
\hline Fla $8624 \mathrm{H}$ & UFL & $\mathrm{HY}$ \\
\hline Fla 8638 B & UFL & $\mathrm{HY}$ \\
\hline Fla 8902LBR & UFL & $\mathrm{HY}$ \\
\hline
\end{tabular}

${ }^{\alpha}$ NCSU: North Carolina State University; UG: United Genetics, SSA: Sakata Seed America; PA: Pennsylvania State University; HMOS: High Mowing Organic Seeds; SYN: Syngenta; CU: Cornell University; NCL: Nutrifert Chile Ltda; UFL: University of Florida; ${ }^{\beta}$ BL: breeding line; HY: hybrid.

2.3. Statistical Analysis. Data collected were analyzed using SAS statistical software version 9.4 (SAS Institute Inc., Cary, NC) using GLM procedure. Analysis of variance was done using randomized complete block design. Correlation analysis was done using Pearson correlation with three levels of significance at $p<0.05,0.01$, and 0.001 . Principle component

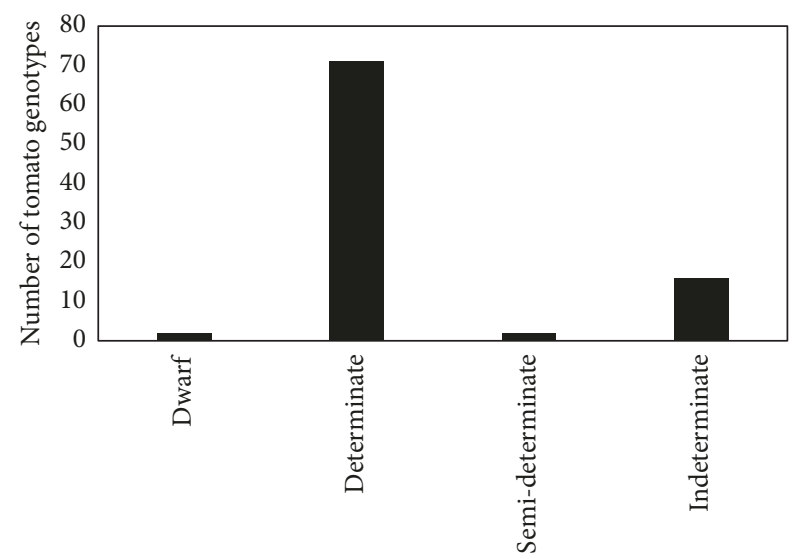

FIGURE 1: Distribution of tomato genotypes based on their growth habit.

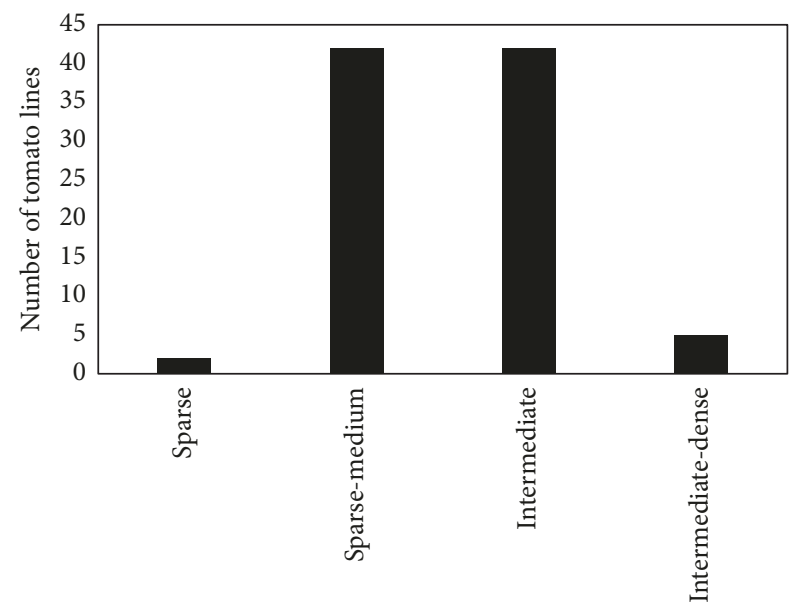

FIGURE 2: Foliage density distribution of tomato genotypes.

analysis and cluster analysis were performed using chord distance coefficient and average linkage method as described by Mazzucato et al. [12].

\section{Results}

3.1. Diversity in Morphological Traits. A wide range of diversity among the genotypes was observed for the traits measured in the study. There were $71(78 \%)$ of determinate lines, $16(17.6 \%)$ indeterminate lines, and $2(2.2 \%)$ dwarf and semi-determinate lines (Figure 1). Different growth type tomato lines started to show variation in their development from seedling stage ranging from 2.15 to 7.4 inches when they were still in 72-cell trays (Table 3 ). All the tomato lines exhibit a linear growth pattern, however, with different rates, after being transplanted in the field until flowers. Foliage densities of these lines also showed variation with a range of sparse (2.1\%), medium-sparse $(46.2 \%)$, intermediate $(46.2 \%)$, and intermediate dense $(5.5 \%)$ as a result of selections for the ease of harvesting and protection of fruits from direct sunlight (Figure 2). The extremes of the foliar density as described in tomato descriptor are difficult to find since they either 


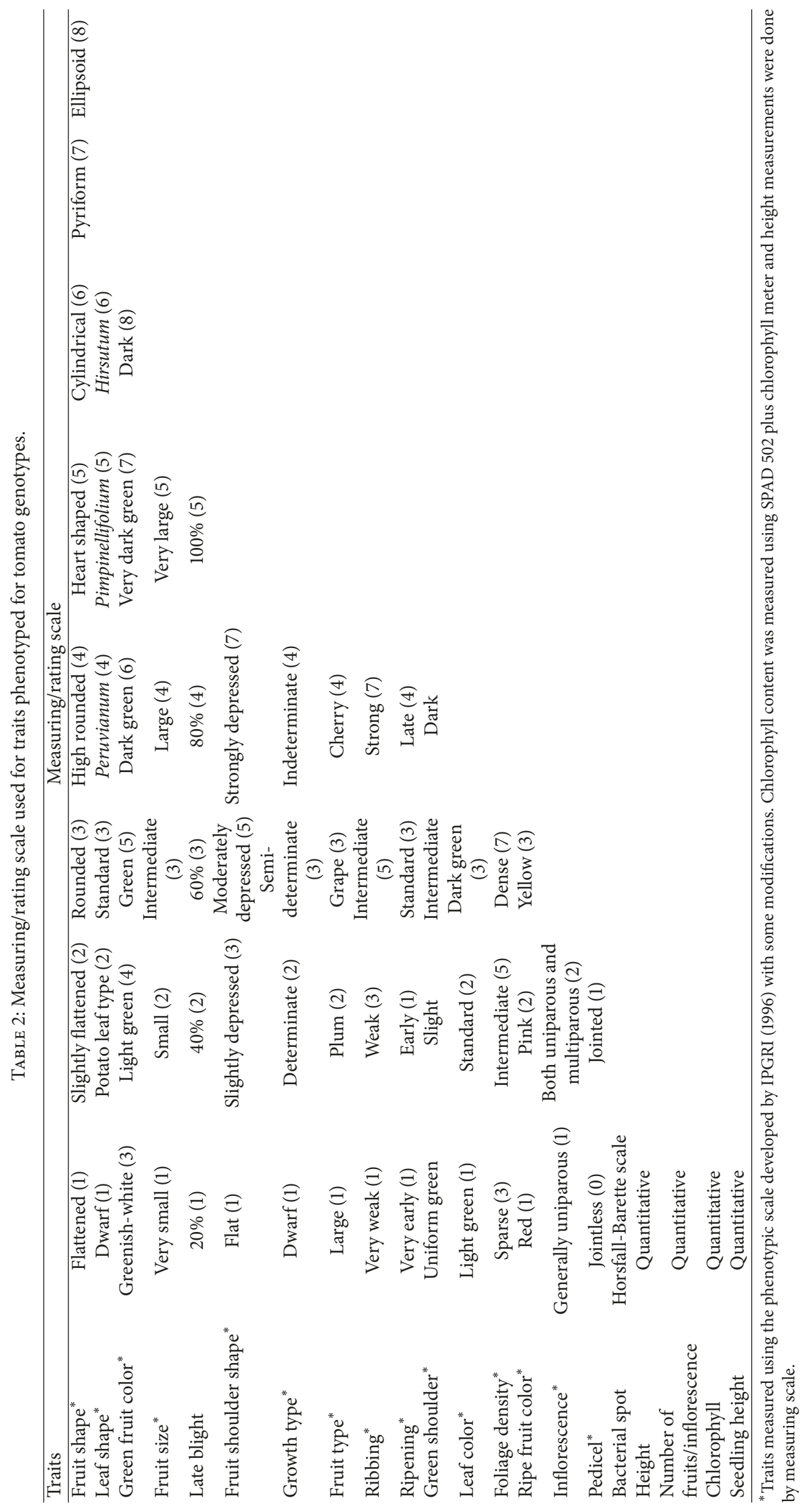


TABLE 3: Analysis of variance (ANOVA), standard deviation (Std. Dev), and minimum and maximum scores of ninety-one fresh-market tomato genotypes for respective morphological traits measured.

\begin{tabular}{|c|c|c|c|c|}
\hline Variable & ANOVA & Std. Dev & Minimum & Maximum \\
\hline Growth type & $2.32^{* * *}$ & 0.77 & 1.50 & 4.00 \\
\hline Seedling height & $4.73^{* * *}$ & 1.08 & 2.15 & 7.40 \\
\hline Average height 1 & $10.23^{*}$ & 2.04 & 4.13 & 18.61 \\
\hline Average height 2 & $17.88^{*}$ & 2.91 & 8.26 & 24.03 \\
\hline Chlorophyll & 52.18 & 3.65 & 42.15 & 62.05 \\
\hline Leaf color & $2.39^{*}$ & 0.41 & 1.50 & 3.00 \\
\hline Leaf shape & $3.08^{* * *}$ & 0.32 & 2.00 & 4.00 \\
\hline Foliage density & $4.34^{* *}$ & 0.55 & 3.00 & 6.00 \\
\hline Inflorescence & $1.33^{* * *}$ & 0.47 & 1.00 & 2.00 \\
\hline Jointless & $0.94^{* * *}$ & 0.24 & 0 & 1.00 \\
\hline Fruit size & $3.49^{* * *}$ & 0.75 & 1.00 & 4.00 \\
\hline Fruit type & $1.67^{*}$ & 1.00 & 1.00 & 5.00 \\
\hline Fruit shape & $2.41^{* * *}$ & 2.08 & 1.00 & 6.00 \\
\hline Fruit per inflorescence & 6.44 & 3.53 & 3.00 & 19.00 \\
\hline Shoulder shape & $3.47^{* * *}$ & 1.51 & 1.00 & 6.00 \\
\hline Ribbing & $3.63^{* * *}$ & 1.31 & 1.00 & 6.00 \\
\hline Green shoulder & $0.26^{* * *}$ & 0.54 & 0.00 & 2.00 \\
\hline Green fruit color & $4.59^{* * *}$ & 1.15 & 3.00 & 8.00 \\
\hline Ripening & $2.06^{* * *}$ & 0.54 & 1.00 & 4.00 \\
\hline Ripe fruit color & 1.25 & 0.47 & 1.00 & 3.00 \\
\hline Bacterial spot & $3.23^{* * *}$ & 1.12 & 1.00 & 9.00 \\
\hline Late blight & $2.90^{* *}$ & 0.65 & 2.00 & 4.50 \\
\hline
\end{tabular}

$*, * *$, and $* * *$ indicate level of significance at $<0.05,<0.01$, and $<0.001$, respectively.

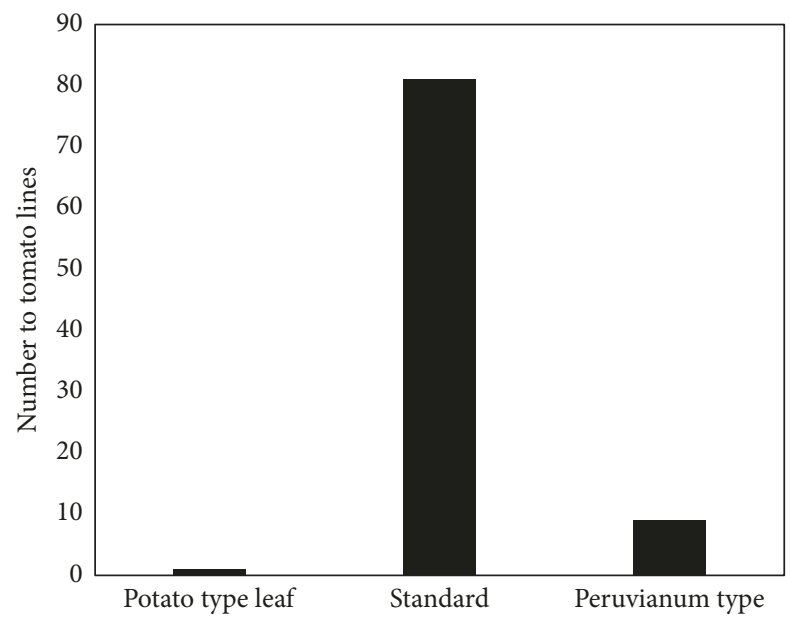

FIGURE 3: Leaf shape distribution of ninety-one fresh-market tomato genotypes.

produce insufficient energy due to less foliage or consume excess energy in maintaining the foliar growth. Most leaf types in those lines exhibited standard leaf type $81(89 \%)$, some had peruvianum leaf type 9 (9.9\%), and only $1(1.1 \%)$ had potato type leaf (Figure 3).

Tomato is grown for fruits and most of the traits measured in this study were related to fruits or associated with fruits. Inflorescence of tomato lines is mainly found as uniparous

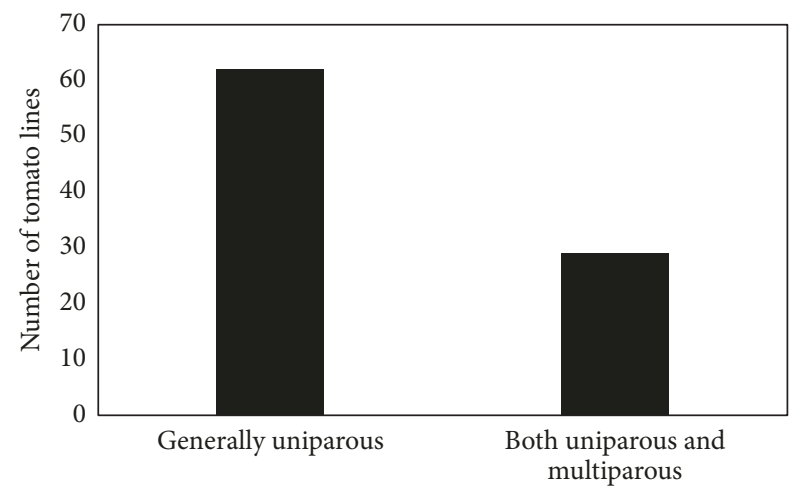

FIGURE 4: Distribution of inflorescence type in ninety-one freshmarket tomato genotypes.

(68.1\%) whereas there were 29 (31.9\%) lines that had both uniparous and multiparous inflorescences in them (Figure 4). Tomato lines in the study had a wide range of distribution regarding number of fruits per inflorescence from 3 to 19 (Table 3). Classification of these lines was done in two categories: $<10$ fruits per inflorescence $(86.7 \%)$ and lines with 10 to 20 fruits per inflorescence (13.3\%) (Figure 5). Pedicels arise from the inflorescence to hold tomato fruits to the plant. With the selection process to facilitate mechanical harvesting, a jointless pedicel varieties are being selected in the breeding programs. In this study, majority of the tomato 


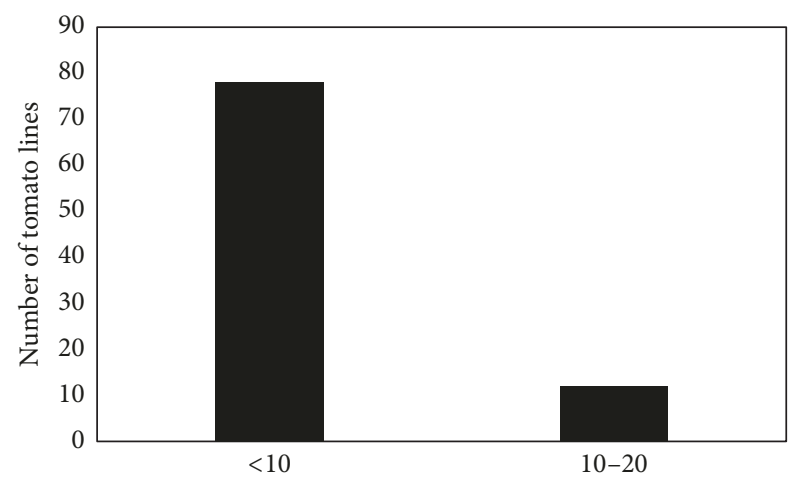

FIGURE 5: Distribution of tomato genotypes in relation to number of fruits per inflorescence.

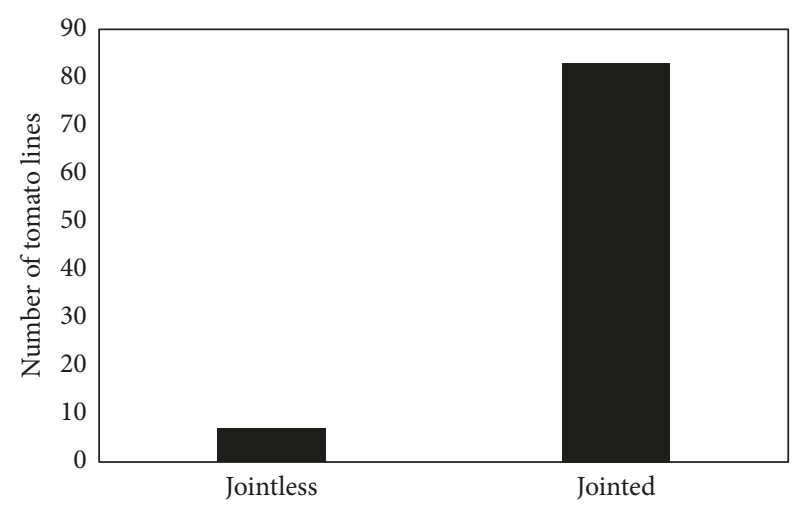

FIgURE 6: Distribution of ninety-one fresh-market tomato genotypes based on pedicel type.

lines had jointed pedicel (92.2\%) in comparison to that of jointless $(7.8 \%)$ (Figure 6). The connection point of pedicel and the fruit in tomatoes is known as shoulder. Tomato lines were also grouped into various classes based on their fruit shoulder shape ranging from 1 to 7 with flat shoulder shape being 1 to strongly depressed being 7 and the distribution is shown in Figure 7. Most of the tomato lines had at least some depression of $81(91.1 \%)$ lines in their shoulder and just $8(8.9 \%)$ of the lines had smooth, flat shoulder shape. Some of the tomato lines exhibited green shoulder in the basal portion of the fruits. This was classified into five classes: 67 tomato lines did not demonstrate green shoulder (74.4\%), 8 lines showed slightly green shoulder (8.9\%), 10 lines showed intermediate green shoulder (11.1\%), and 5 lines had green shoulder (5.6\%) (Figure 8). Tomato lines in the study also exhibited different forms of edges before they got softened after ripening. This trait was classified into seven groups ranging from very weak ribbing as 1 to strong ribbing as 7 (Figure 9). Fresh-market tomatoes have been recently bred for different colors. Tomato lines in this study displayed three predominant colors in tomatoes: red (89.5\%), pink (5.8\%), and yellow (4.7\%) (Figure 10). Along with variation in ripe fruit colors, there is also significant variation in duration of ripening of tomatoes. With selections for early maturity, there were 4 lines that had very early maturity (4.4\%), 5 lines

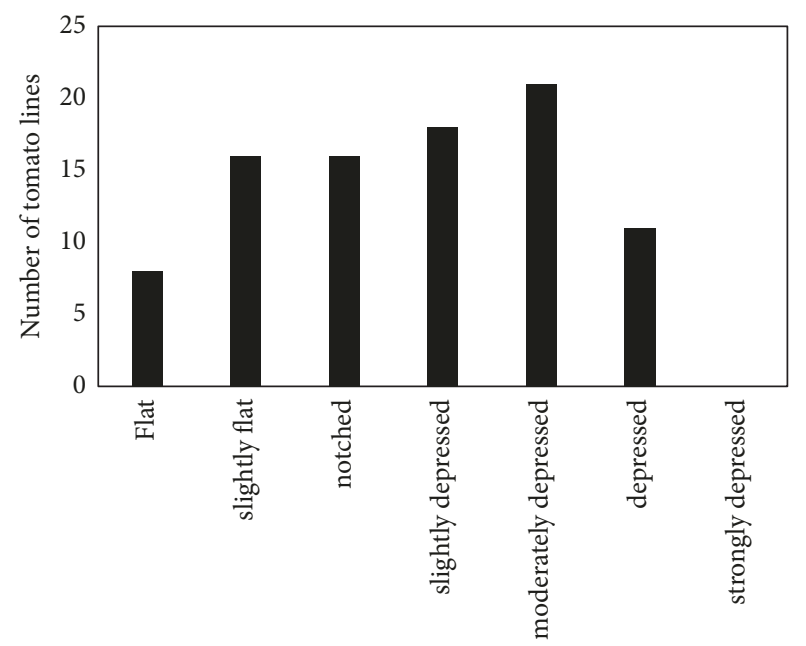

Figure 7: Distribution of ninety-one fresh-market tomato genotypes based on shoulder shape of fruits.

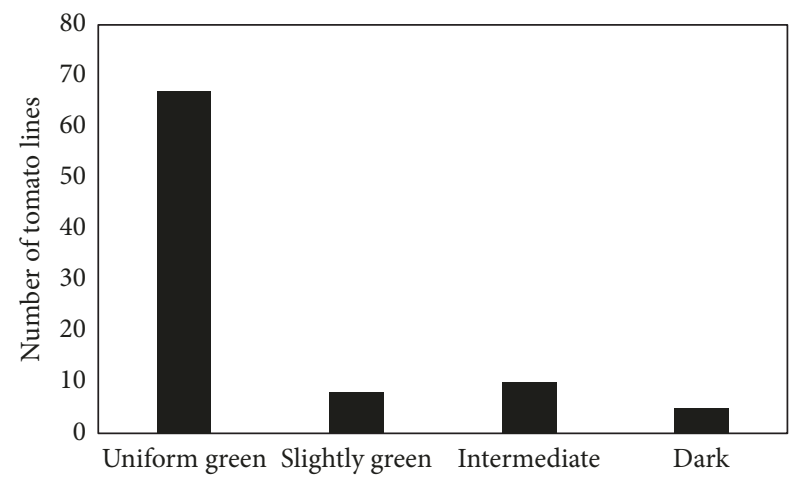

Figure 8: Distribution of ninety-one fresh-market tomato genotypes based on green shoulder.

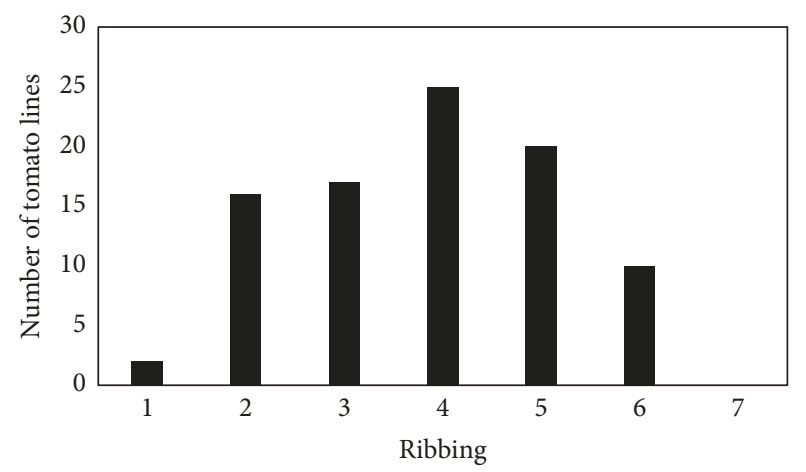

FIGURE 9: Distribution of ninety-one fresh-market tomato genotypes based on ribbing on fruits. The scale ranging from 1 to 7 with 1 being no or very weak ribbing and 7 being the strong.

with early maturity (5.5\%), 77 lines with standard maturity (84.6\%), and 5 lines with late maturity (5.5\%) (Figure 11).

Fruits were classified into five different categories based on their sizes. There was 1 very small sized fruit (1\%), followed by 3 small sized (4\%), 20 intermediate (22\%), 11 


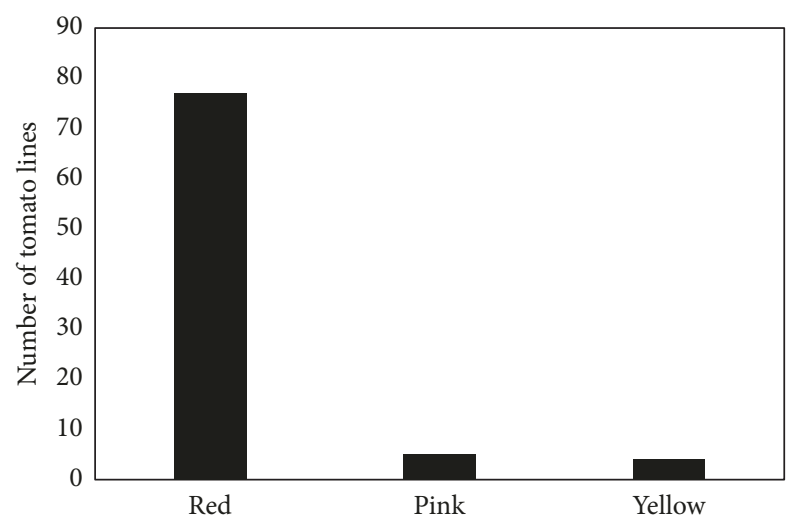

FIGURE 10: Distribution of ninety-one fresh-market tomato genotypes based on ripe fruit color.

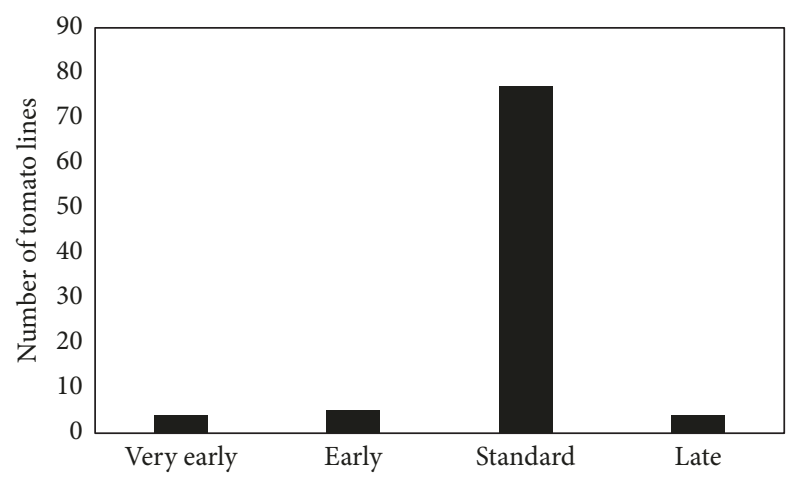

Figure 11: Distribution of ninety-one fresh-market tomato genotypes based on fruit ripening.

large (12\%), and 55 very large (61\%) fruits (Figure 12). Fruits were classified based on their types into four categories: cherry $(1 \%)$, grape $(13 \%)$, plum $(16 \%)$, and large $(70 \%)$ (Figure 13). According to the shape of fruits, tomato lines were categorized into six classes: flattened (60\%), slightly flattened $(6 \%)$, highly rounded $(1 \%)$, rounded $(8 \%)$, heartshaped (4\%), and cylindrical (21\%) (Figure 14).

3.2. Correlation Analysis. All the data measured in the study were also analyzed for correlations, and the results are presented in Table 4. There were only a few correlations that were very high, and most of the traits either were not significantly correlated or, if significant, were not very high. This was not surprising because of the long tomato breeding history and moving of genes from one type of tomato into another had significant impact on this. Correlations between the seedling heights and average heights were 0.66 and 0.50 , respectively, which were significant at $P<0.001$. The correlation decreased in the second height in comparison to the first because of the lines that had $b r$ gene and determinate growth habit which led them to grow normally during the seedling stage but after seedling stage, the internodes of those with $b r$ gene developed shorter than that of determinate lines and growth of determinate lines were checked after flowering whereas semi-determinate and indeterminate lines continued to grow as flowering occurred. As the trend of plant growth was similar in the postseedling stage, the correlation between the two average heights also increased as expected (0.78, $P<0.001)$. The correlation between the inflorescence and growth type was $0.54(P<0.001)$ which indicates that semi-determinate and indeterminate growth types are likely to have branched inflorescence in comparison to that of determinate types. However, the correlation was not very high because of some grape and plum tomatoes that have been developed with determinate growth habit but they exhibit the branched inflorescences. Fruit size was negatively correlated $(-0.37, P<0.001)$, with growth type indicating that semi-determinate and indeterminate growth type plants are likely to have relatively smaller fruit sizes as compared to dwarf and determinate growth type. However, the correlation was comparatively low because of the development of grape and plum type tomatoes that are of determinate types and have smaller fruit sizes. Inflorescence type was significantly negatively correlated with the fruit size $(-0.71, P<0.001)$. This is important to produce different fruit size tomato. If the inflorescence type is branched giving rise to an increased number of flowers, it will be likely to hold more fruits. However, a plant will not be able to handle many larger size tomato fruits in one inflorescence or many in comparison to smaller size tomato fruits. Due to smaller size, a large number of fruits can develop well in a cluster whereas larger fruits have to compete for space, nutrients and protection, or need of sunlight being in the same cluster. Smaller fruits tend to be more of cherry, grape, and plum type whereas larger tomatoes tend to be flat. Hence, fruit size is highly correlated with fruit type $(0.75, P<0.001)$. Another important trait of fruit is fruit shape on which a lot of work has been done in the breeding programs. Despite the development of different types of tomato fruits with various shapes, the correlation between these traits is still significant $(0.43, P<0.001)$. Fruit load per inflorescence is highly dependent on fruit characteristics and growth type. As expected, with an increase in fruit size, the number of fruits per inflorescence decreases significantly $(-0.83, P<0.001)$. Fruit types like cherry and grapes had a higher number of fruits per inflorescence followed by plum and larger fruit types $(0.65, P<0.001)$. Correlation among tomato plant growth type and number of fruits per inflorescence was significant $(0.55, P<0.001)$ although not very high. Shoulder shapes of larger fruits were found to be depressed to a greater intensity in comparison to smaller fruits $(0.75, P<0.001)$ whereas negative correlation was observed between shoulder shape and fruit type and fruit shape $(-0.69, P<0.001$, and $0.68, P<0.001$, resp.). Flat shaped large fruits had a higher intensity of shoulder depression whereas cherry, grape, and plum types showed lower depression in shoulder shape. Shoulder shape was also, although not very high, significantly negatively correlated with number of fruits per inflorescence $(0.59, P<$ 0.001). It was also observed that fruits demonstrated higher ribbing when shoulder shape depression was higher $(0.76$, $P<0.001)$. Fruits that developed into flattened shape after ripening were observed to have high ribbing and those that were heart-shaped or round had low ribbing intensity $(0.63$, $P<0.001)$. Similarly, smaller fruits showed less ribbing 


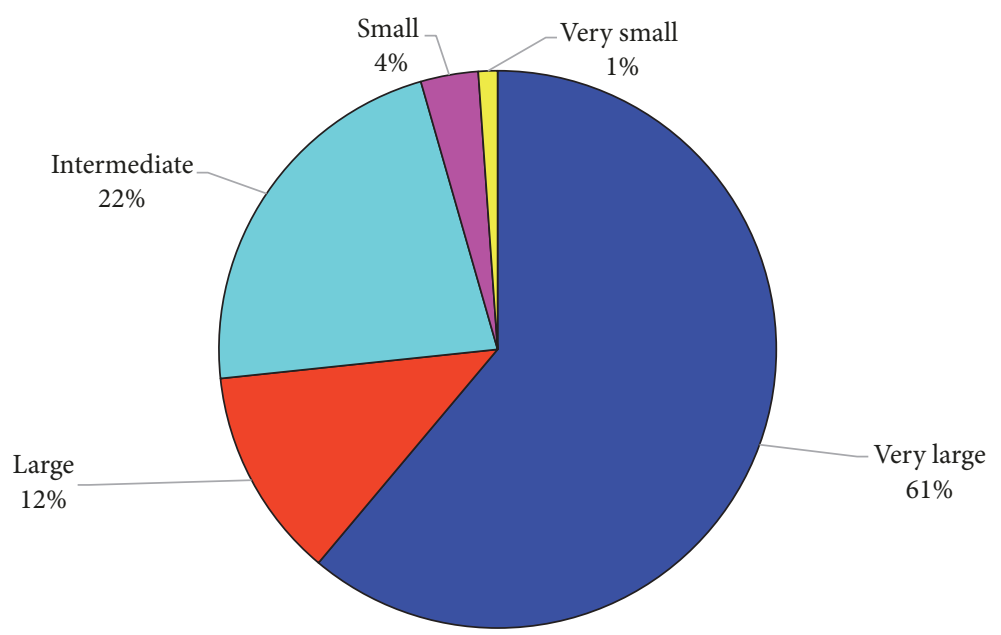

FIGURE 12: Distribution of ninety-one fresh-market tomato genotypes based on fruit size.

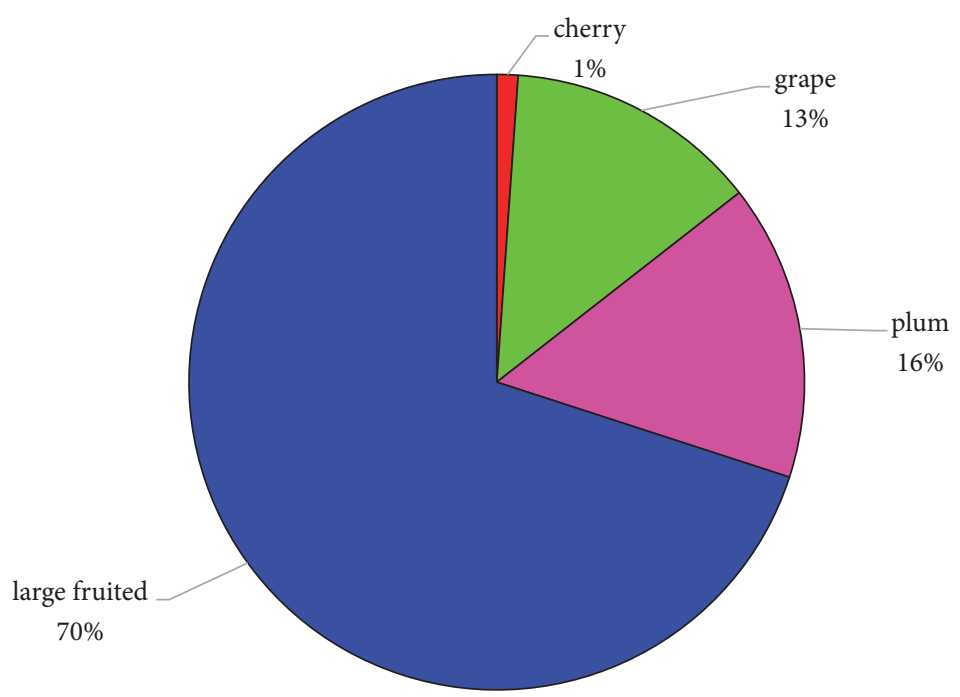

FIGURE 13: Distribution of ninety-one fresh-market tomato genotypes based on fruit type.

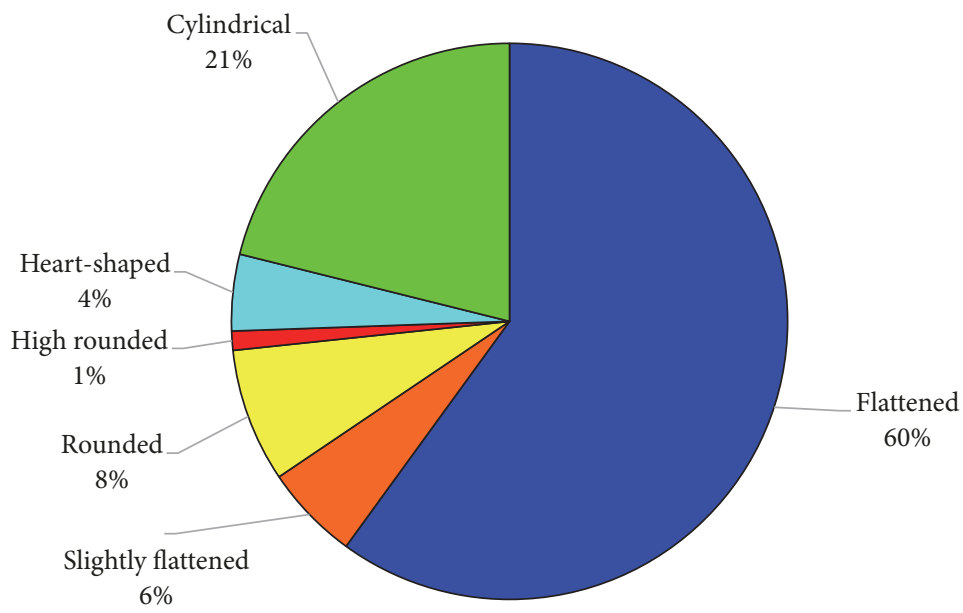

FIGURE 14: Distribution of ninety-one fresh-market tomato genotypes based on fruit shape. 


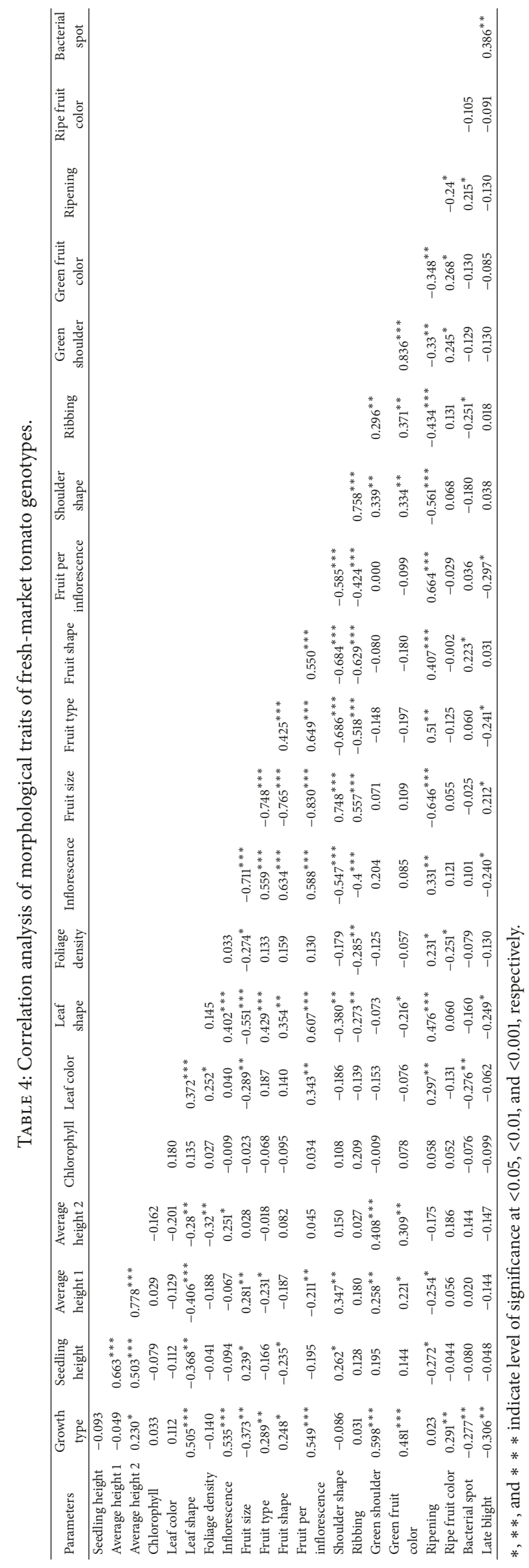


TABLE 5: Eigenvalues of the correlation matrix of principal component analysis of ninety-one fresh-market tomato genotypes.

\begin{tabular}{lcccc}
\hline PCA & Eigenvalue & Difference & Proportion & Cumulative \\
\hline 1 & 9.0367821 & 3.4435029 & 0.3012 & 0.3012 \\
2 & 5.5932792 & 2.7534108 & 0.1864 & 0.4877 \\
3 & 2.8398684 & 1.0918018 & 0.0947 & 0.5823 \\
4 & 1.7480666 & 0.4301305 & 0.0583 & 0.6406 \\
5 & 1.3179361 & 0.1266968 & 0.0439 & 0.6845 \\
6 & 1.1912393 & 0.1131292 & 0.0397 & 0.7242 \\
7 & 1.0781102 & 0.1113939 & 0.0359 & 0.7602 \\
8 & 0.9667163 & 0.2271584 & 0.0322 & 0.7924 \\
9 & 0.739558 & 0.0453556 & 0.0247 & 0.8171 \\
10 & 0.6942024 & 0.0093849 & 0.0231 & 0.8402 \\
\hline
\end{tabular}

while larger fruits had higher degree of ribbing $(0.56, P<$ 0.001 ) and fruit type was significantly negatively correlated to ribbing $(-0.52, P<0.001)$ indicating that ribbing intensity gradually increases from cherry, grape, and plum to large tomato fruits. Green shoulder on the basal end of tomato fruits was found to be correlated with growth type (0.6, $P<0.001)$ indicating dwarf and determinate type of tomato lines are less likely to have a green shoulder in their fruits in comparison to semi-determinate and indeterminate type tomato lines. Fruits with green shoulder resulted in darker green looking fruits with highly significant correlation $(0.84$, $P<0.001)$ with green fruit color. Fruit ripening time was found to be correlated to different traits at a different level. Increase in fruits per inflorescence was the most highly correlated trait with fruit ripening $(0.66, P<0.001)$ followed by fruit size $(0.65, P<0.001)$ and moderately correlated with shoulder shape $(0.56, P<0.001)$ and fruit type $(0.51$, $P<0.01)$. Bacterial spot caused by Xanthomonas perforans and late blight caused by Phytophthora infestans are one of the major problems in fresh-market tomato. Although there were some statistically significant correlations found between other traits and these diseases but those correlations were very low (Table 3 ). However, correlations between these two diseases per se were the highest between them $(0.39, P<$ $0.01)$. The incidence was measured later in the season when the diseases had enough time to establish themselves in the plants. This could be due to decreased immunity of plants once they are infected by one disease that compromises the immunity of the plants increasing the susceptibility of the plant for other pathogens prevalent in the environment. There were traits that did not show any significant correlations with any other traits like chlorophyll content, leaf color which indicates that selection procedure in modern tomato lines has already led to the desired level of these traits for the current production.

3.3. Principal Component Analysis and Cluster Analysis. Principal component analysis (PCA) of the tomato genotypes indicated that six principal components (PC) described more than $70 \%$ of the variation (Table 5). The first two PCs include traits that are of most importance to the tomato production. PCl includes the seedling and plant heights and fruit traits like green shoulder and fruit color during developmental stage and PC2 contains other fruit traits like inflorescence type, number of fruits per inflorescence, fruit type, and fruit shape and leaf shape. These two PCs explain nearly half of the variation $(48.77 \%)$ present in the study (Table 5).

Cluster analysis of the tomato genotypes generated two major divisions that separate majority of tomato lines developed at North Carolina tomato breeding program with rest of others including grape type genotypes like Smarty, Mountain vineyard, and Mountain Honey, plum type genotypes like NCEBR3, NCEBR5, NCEBR6, and NC30P, and large type genotypes like NCHS1 from the program (Figure 15). Both clusters contain a combination of different types of genotypes which is a clear indication that different traits have been significantly transferred into the new lines being developed to increase the value of new cultivars, which was expected. These divisions were primarily divided into three clusters which were further divided into groups either constituting tomato genotypes with similar or different characteristics. When the groups within each cluster were observed, a clear distinction between them was observed.

The first cluster consists of tomato lines that are advanced breeding lines, hybrids, and advanced selections from various breeding programs. In this cluster, 141G, 143G, 145G, $147 \mathrm{G}$, and $148 \mathrm{G}$ are of indeterminate growth type with branched inflorescence containing up to five large size fruits. Other tomato lines in this group Fla $8638 \mathrm{~B}$, Fla 8902LBR, NC2CELBRxPAU351-Y, YCBT-1 x-NC132S, $335 \mathrm{x}$ NC2CELBR, NC2CELBRxPAU332, NC2CELBR x C23-3, NC132S x C23-3, $335 \times$ NC132S, YCBT-1 x NC2rinEC, PAU332xNC2rinEC, NC132SxPAU332, NC132SxPAU351-Y, VFT Vendor $x$ CUTR 2nd Gen 124116-4, NC33EB1 x CUTR 1st Gen CUTR, Summerpick, NC33EB1 x CUTR 2nd Gen 124116-4, Richmond, Brickyard are determinate type with unbranched inflorescence containing up to six fruits/inflorescence. Fruits of these lines are large except VFT Vendor x CUTR 2nd Gen 124116-4 and NC33EB1 x CUTR 2nd Gen 124116-4 which are of intermediate size.

The second cluster consisted of two main subgroups. First subgroup consisted of a combination of different types of tomato lines from different breeding programs. This cluster consists of PSGH-13-33, Monticello, Ridge Runner, PSFH-1319, PSFH-13-47, PSGH-13-16, XTM0017, XTM262, UF 1104113, UG1155013, NC 161L, and Mountain Rouge. Among these lines PSGH-13-33, PSGH-13-16, and Mountain Rouge are indeterminate types. PSGH-13-33 and PSFH-13-47 had a plum type, and PSGH-13-16 had elongated, grape type fruits whereas rest of all had large fruits.

Second subgroup of tomato lines from second major division consisted of lines NC 5Grape, Mountain Honey, Mountain Vineyard, and Smarty. These lines had indeterminate growth type, branched inflorescence containing more than 13 fruits/inflorescence which were small and slightly round to elongated in shape.

Third subgroup consisted of a combination of a different type of tomato lines regarding fruit characteristics. This included lines Summit, Sun Leaper, Piedmont, NCHS1, Plum Dandy, NCEBR6, Plum Crimson, NCEBR3, NCEBR5, NCEBR7, NCEBR8, and NC30P. All of these lines were 


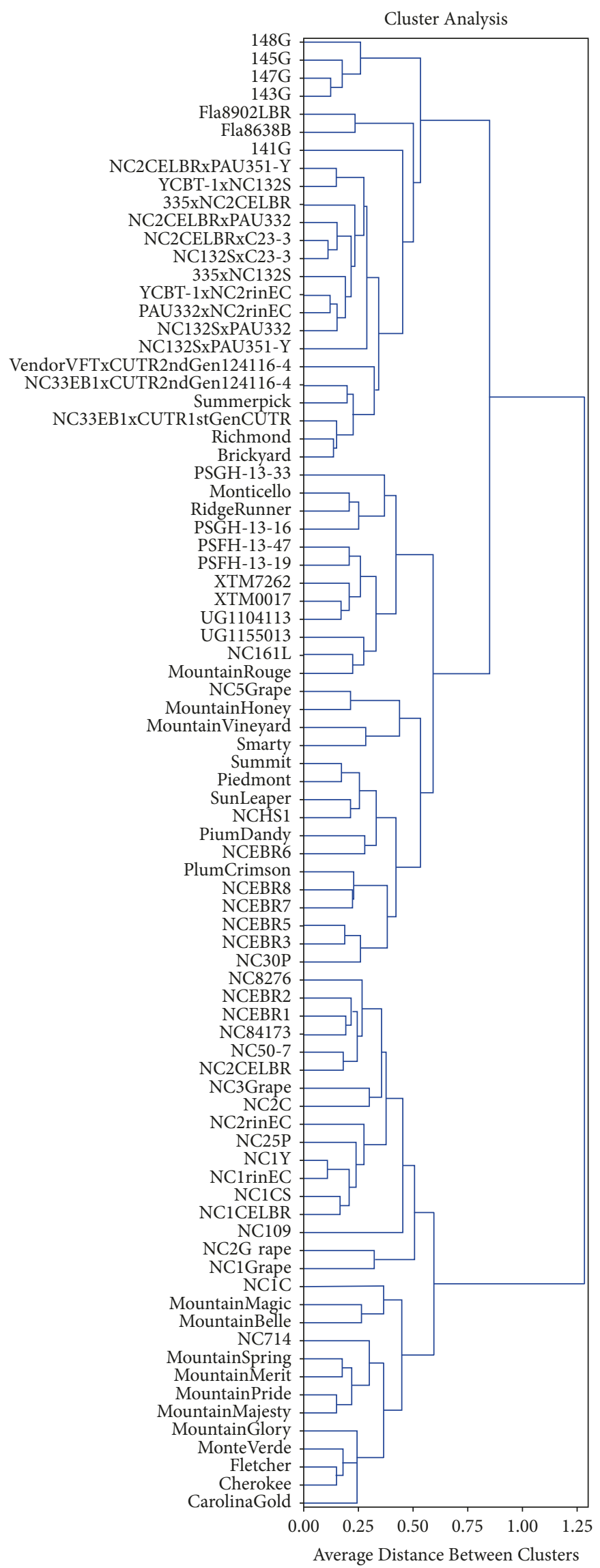

FIGURE 15: Cluster analysis of ninety-one fresh-market tomato genotypes based on average distance method. 
determinate. However, among them, Summit, Sun Leaper, Piedmont, and NCHS1 had large, flattened shaped fruits when ripe. Inflorescence of these lines was unbranched with up to 5 fruits per inflorescence. Other lines Plum Crimson, NCEBR3, NCEBR5, NCEBR7, NCEBR8, and NC30P had small to medium sized plum-shaped fruits ranging from five to nine fruits per inflorescence depending on lines.

The third cluster consisted of few small subgroups. First subgroup in this cluster consisted of NC2CELBR, NC50-7, NC8276, NC84173, NCEBR1, and NCEBR2. These lines are of determinate growth type with uniparous inflorescence containing up to five fruits per inflorescence. These fruits were medium to large and of flattened shape when ripe. These lines are also important regarding fungal diseases because of their resistance to fusarium wilt and verticillium wilt. Second subgroup consisted of NC1CELBR, NC1CS, NC1rinEC, NC1Y, NC2rinEC, and NC25P which were determinate lines with up to 5 fruits per inflorescence. All the lines except NC25P are large fruited with uniparous inflorescence; however, the inflorescence of NC-25P was sometimes multiparous with elongated, plum type fruits. Third subgroup of NC 1Grape and NC 2Grape was observed which are of indeterminate growth type containing slightly elongated grape type fruits that are small. Inflorescence of these lines is multiparous having more than 15 fruits in a cluster. NC2C and NC 3Grape formed fourth subgroup which had branched inflorescence with more than ten small sized fruits. However, NC-109 was not clustered in any subgroup which was a determinate line with plum type fruits. Fifth subgroup consisted of tomato lines NC 714, Mountain Spring, Mountain Merit, Mountain Pride, Mountain Majesty, Mountain Glory, Mountain Verde, Fletcher, Cherokee, and Carolina Gold which are of determinate growth types with large fruit types with the mostly flattened shape when ripe. A second cluster consisting of Mountain Magic, NC 1C, and Mountain Belle exhibited different growth habit but have multiparous inflorescence with more than ten fruits per inflorescence, cherry type, very small fruits.

\section{Discussion}

Domestication and years of selection processes imposed on tomato have led to severely decreased genetic variability [1315]. Domestication of tomato was based on nontoxic, palatable, and nutritious features. Qualities like flavor, juiciness, and other consumer-desirable characteristics became important after domestication phase. These traits were incorporated by farmers based on selection methods without or with the very minimum breeding approach. Landraces display greater diversity in comparison to modern cultivars because of desirable uniformity to best fit in the production system [16]. It has been estimated that modern tomato cultivars contain $<5 \%$ of the genetic variation that is present in their wild relatives [17]. It is difficult to increase diversity just with classical breeding that depends on naturally occurring recombination, by crossing two modern cultivars. With the involvement of private breeding companies in the new cultivars production in the tomato industry, it has become very competitive and hence developing new traits using wild germplasm is not feasible with significant linkage drag. Therefore, it is not surprising to see the increasing relativity among the modern cultivars with decreasing diversity as agriculture becomes monoculture rather than diversified. Although modern tomato shows higher phenotypic diversity, there has been a loss of genetic diversity in modern cultivars as compared to the wild or landraces. It has been studied previously that the genetic diversity of tomato lines was low $[12,16]$. Morphological traits have been used to assess the diversity in different germplasms, sometimes with molecular markers [12, 17-19]. Ninety-seven tomato accessions from Iran and Turkey were classified into five clusters [17], sixtyseven lines from Argentina were classified into three clusters [18] and fifty lines, including both cultivated and wild, were classified into six clusters [19].

Based on consumption, the tomato has been bred separately for fresh-market and processing industries. As a result, cultivars yielding fruits with various sizes, shapes, and colors and different production techniques were developed [20, 21]. With tomato breeding being widely performed, after 1930, the goal of tomato breeding has been primarily yield and productivity followed by disease resistance to maintain production in challenging environment. Identification of important phenotypic trait in wild or related germplasm, their genetic basis, and introgression of those traits into advanced modern lines have been key to the development of new cultivars in tomato. With fresh-market tomato, some of the important traits that have been of main focus for producer are yield or size, disease and insect resistance, heat and other abiotic stress tolerance, uniform/synchronous ripening, and harvesting with focus in mechanization; for marketing are longer shelf life, minimum handling, and shipping damage; and for consumer are flavor and taste, appearance/color, and forms of use like salad and cooking [20-22]. The jointless (j2) allele [23] was introgressed from S. cheesmanii. Compact fruit set by determinate growth, $s p$ for self-pruning, was discovered from a natural mutation in the early 20 th century. Four genes are known to control fruit shape: sun [24] and ovate [25] control elongated shape like in Roma type whereas fasciated (FAS) [26] and locule number (LC) [27] control fruit locule and flat shape.

There are different types of fresh-market tomato developed according to the need: large fruited, plum-shaped also known as Roma tomato, grape type, and cherry type. Large fruited and plum type are used in cooking and meals whereas grape and cherry types are primarily used as fresh fruits and in salads. Cherry type tomato developed due to the genetic admixture of $S$. pimpinellifolium and cultivated accessions $[28,29]$. Wild tomato is of indeterminate growth type; however advanced tomato cultivars that are commercial grown in fresh-market production system are determinate making it easier to contain them over plastic beds and manage them while pruning, staking and tying with the string, spraying, and harvesting as they demand less management practice in comparison to the wild lines. With the identification of determinate and dwarf growth habit, these traits are highly being incorporated into other cultivars including all types of tomatoes. As a result, there are determinate large fruited, plum, and grape type tomato lines already released. Higher 
negative correlation between inflorescence and fruit size indicates that despite the introgression of determinate trait in among all the new cultivars, smaller fruit sized tomato lines tend to have semi-determinate or determinate growth habit. One of the reasons for this could be the growth trait linked with fruit size or taste. Small size fruits have high total soluble sugars in comparison to larger fruits. Indeterminate growth may be preferred in smaller sized fruit lines for increased production for a longer season. However, there are varieties like NC-3 Grape which are determinate [30]. Introgression of disease and insect resistant genes in all newly being developed cultivars has also been very common in all types of tomatoes $[9,31]$. Cherry or grape type tomato has been developed for consumption like other fruits and needs to contain the similar amount and balanced combination of sugar and acid. With increase in fruit size, the amounts of soluble sugars and acids get diluted and decrease [32]. Plum and large type fruits have been developed for cooking or to be a component of meals so yield remains the focus rather than its constituents. This was also observed in this study and was the reason for higher correlation between fruit size and fruit types. When large fruits ripe, they soften, and due to the size, the fruits become flattened or globular in size whereas ripe plum fruits become smoother but remain cylindrically oblong keeping the elongated shape. Due to smaller shape of cherry and grape types, they remain firm and maintain their elongated and round shape. Because of this nature, correlation between the fruit type and size remained higher although with the breeding techniques large fruits are being bred for firmness that keep the fruit round shaped rather than turn into flattened when ripe like fruits of NC84173 are round to elongated round even at harvesting and when ripe [33]. Number of fruits grown in an inflorescence also highly depends on size of the fruits as was seen in this study. If the fruits are smaller, more number of fruits can be developed in one inflorescence whereas when the fruit size increases, increased energy drain to the inflorescence remains insufficient to develop equal number of fruits compared to that of smaller sizes like grape and cherry type. Larger fruits also compete for space, sunlight, and protection by foliage and therefore limited number of fruits develop into mature fruits even when there are more flowers in an inflorescence during the time of floral development. Shoulder shape of the fruits increases when the fruits development occurs and outgrows the region where the pedicel connects the fruits. This is more prominent in large fruits and relatively less in plum, grape, and cherry type fruits because of the relatively less increase in the size of these types of fruits in comparison to the larger fruits. Fruits that are smaller in size are expected to ripe early because of their faster development and reaching maturity. However, early maturity is also a very desirable trait in all types of tomato and hence is being introgressed into different types of tomato including plum and large for greater value. Similarly, varieties with smaller sized fruits are bred with larger sized fruit varieties to develop fruits with standard ripening time and multiple colors.

There have been many types of researches on finding resistance to diseases like bacterial spot; however, no single cultivar has been developed that can resist all races of
Xanthomonas causing bacterial spot making this disease a very difficult problem to overcome [34]. This explains the low correlation of bacterial spot with any other traits observed in this study as seen in a previous study [35], whereas resistance to fungal diseases like early blight, late blight, fusarium, and verticillium wilts and nematode resistance have been identified and are already being introgressed in new varieties [36]. Pyramiding the genes for resistance to diseases and pests has been one of the major goals of tomato breeding programs. Modern varieties developed have been reported to be introgressed with up to 12 different diseases and pest resistant genes. This was also observed in the cluster analysis where different tomato types were clustered into one or different groups indicating the presence of common traits across all the tomato lines regardless of their origin or fruit characteristics $[37,38]$.

\section{Conclusion}

Morphological characteristics of tomato lines, from different origins being actively used in developing new cultivars, advanced selections for inbred development, or lines being tested as putative cultivars were used in this study to assess diversity present in fresh-market tomato. Higher correlations between fruit traits indicate the necessity of those traits to remain related to higher quality and yield. The greater number of large sized tomato fruits per inflorescence will lead to low-quality fruits whereas a lower number of cherry or grape type fruits per cluster result in lower yield. Lower correlations between some traits and fruit types indicated the introgression of those traits in all fruit types like determinate growth habit is desirable for all types of fruits for better production management, not only early fruit maturity but standard and late maturity are also required for longer seasonal production as these trends could be observed in the study. Grouping of different types of tomato lines in one cluster indicates the most desirable traits, including disease resistance, being transferred into all types of tomato lines being developed by breeding programs, whereas grouping of similar tomato lines with specific traits like grape type tomato indicates the unique features of the cluster that is preferred only to have in those types of tomato lines. As limited number traits are being commonly introgressed into the modern tomatoes across the world, the lost alleles during the domestication and rigorous selections can be brought back by crossing wild lines with the cultivated species. Genomics can play an important role in opening new perspectives and opportunities to layout the divergence over time and help in bringing characteristics that were lost or missed during domestication and selection. With the availability of the genome sequence of tomato and developed molecular marker information, use of wild relatives can be strongly reinforced.

\section{Disclosure}

Current address of Krishna Bhattarai is Gulf Coast Research and Education Center and Department of Environmental Horticulture, University of Florida, 14625 County Road 672, Wimauma, FL 33598, USA. 


\section{Conflicts of Interest}

The authors declare that they have no conflicts of interest.

\section{Acknowledgments}

This research was supported by the funding grant of North Carolina Tomato Growers' Association and USDA Hatch Project. The authors would like to thank different public and private breeding programs that contributed tomato genotypes for the research.

\section{References}

[1] C. M. Rick, “Tomato (family Solanaceae)," in Evolution of crop plants, N. W. Simmonds, Ed., pp. 268-273, Longman Publications, 1976.

[2] C. E. Williams and D. A. St. Clair, "Phenetic relationships and levels of variability detected by restriction fragment length polymorphism and random amplified polymorphic DNA analysis of cultivated and wild accessions of Lycopersicon esculentum," Genome, vol. 36, no. 3, pp. 619-630, 1993.

[3] A. Khadivi-Khub, Z. Zamani, and N. Bouzari, "Evaluation of genetic diversity in some Iranian and foreign sweet cherry cultivars by using RAPD molecular markers and morphological traits," Horticulture, Environment and Biotechnology, vol. 49, pp. 188-196, 2008.

[4] P. J. Terzopoulos and P. J. Bebeli, "Phenotypic diversity in Greek tomato (Solanum lycopersicum L.) landraces," Scientia Horticulturae, vol. 126, no. 2, pp. 138-144, 2010.

[5] K. Nikoumanesh, A. Ebadi, M. Zeinalabedini, and Y. Gogorcena, "Morphological and molecular variability in some Iranian almond genotypes and related Prunus species and their potentials for rootstock breeding," Scientia Horticulturae, vol. 129, no. 1, pp. 108-118, 2011.

[6] H. Fufa, P. S. Baenziger, B. S. Beecher, I. Dweikat, R. A. Graybosch, and K. M. Eskridge, "Comparison of phenotypic and molecular marker-based classifications of hard red winter wheat cultivars," Euphytica, vol. 145, no. 1-2, pp. 133-146, 2005.

[7] N. Ranc, S. Mũos, S. Santoni, and M. Causse, "A clarified position for solanum lycopersicum var. cerasiforme in the evolutionary history of tomatoes (solanaceae)," BMC Plant Biology, vol. 8, article no. 130, 2008.

[8] S. D. Tanksley and S. R. McCouch, "Seed banks and molecular maps: Unlocking genetic potential from the wild," Science, vol. 277, no. 5329, pp. 1063-1066, 1997.

[9] C. M. Rick and R. T. Chetelat, "Utilization of related wild species for tomato improvement," Acta Horticulturae, no. 412, pp. 21-38, 1995.

[10] IPGRI, "Tomato Descriptors," in Proceedings of the International. Plant Genetic Resources Institute, Rome, Italy, 1996.

[11] K. L. Ivors and F. J. Louws, North Carolina Agricultural Chemicals Manual, College of Agriculture and Life Sciences, North Carolina State University, 2013.

[12] A. Mazzucato, R. Papa, E. Bitocchi et al., "Genetic diversity, structure and marker-trait associations in a collection of Italian tomato (Solanum lycopersicum L.) landraces," Theoretical and Applied Genetics, vol. 116, no. 5, pp. 657-669, 2008.

[13] K. Hammer, “Das Domestikationssyndrom,” Die Kulturpflanze, vol. 32, no. 1, pp. 11-34, 1984.
[14] S. Grandillo and S. D. Tanksley, "QTL analysis of horticultural traits differentiating the cultivated tomato from the closely related species Lycopersicon pimpinellifolium," Theoretical and Applied Genetics, vol. 92, no. 8, pp. 935-951, 1996.

[15] Y. Bai and P. Lindhout, "Domestication and breeding of tomatoes: what have we gained and what can we gain in the future?" Annals of Botany, vol. 100, no. 5, pp. 1085-1094, 2007.

[16] J. Cebolla-Cornejo, S. Roselló, and F. Nuez, "Phenotypic and genetic diversity of Spanish tomato landraces," Scientia Horticulturae, vol. 162, pp. 150-164, 2013.

[17] M. Henareh, A. Dursun, and B. A. Mandoulakani, "Genetic diversity in tomato landraces collected from Turkey and Iran revealed by morphological characters," Acta Scientiarum Polonorum, Hortorum Cultus, vol. 14, no. 2, pp. 87-96, 2015.

[18] X. Hu, H. Wang, J. Chen, and A. W. Yang, "Genetic diversity of Argentina tomato varieties revealed by morphological traits, simple sequence repeat, and single nucleotide polymorphism markers," Pakistan Journal of Botany, vol. 44, no. 2, pp. 485-492, 2012.

[19] R. Zhou, Z. Wu, X. Cao, and F. L. Jiang, "Genetic diversity of cultivated and wild tomatoes revealed by morphological traits and SSR markers," Genetics and Molecular Research, vol. 14, no. 4, pp. 13868-13879, 2015.

[20] G. R. Rodríguez, S. Muños, C. Anderson et al., "Distribution of SUN, OVATE, LC, and FAS in the tomato germplasm and the relationship to fruit shape diversity," Plant Physiology, vol. 156, no. 1, pp. 275-285, 2011.

[21] G. Bauchet and M. Causse, "Genetic diversity in tomato (Solanum lycopersicum) and its wild relatives," in Genetic diversity in plants, M. Çaliskan, Ed., pp. 133-162, InTechOpen, Rijeka, Croatia, 2012.

[22] Q. Gascuel, G. Diretto, A. J. Monforte, A. M. Fortes, and A. Granell, "Use of natural diversity and biotechnology to increase the quality and nutritional content of tomato and grape," Frontiers in Plant Science, vol. 8, article no. 652, 2017.

[23] E. J. Szymkowiak and E. E. Irish, "JOINTLESS suppresses sympodial identity in inflorescence meristems of tomato," Planta, vol. 223, no. 4, pp. 646-658, 2006.

[24] E. van der Knaap, A. Sanyal, S. A. Jackson, and S. D. Tanksley, "High-resolution fine mapping and fluorescence in Situ hybridization analysis of sun, a locus controlling tomato fruit shape, reveals a region of the tomato genome prone to DNA rearrangements," Genetics, vol. 168, no. 4, pp. 2127-2140, 2004.

[25] H.-M. Ku, S. Doganlar, K.-Y. Chen, and S. D. Tanksley, "The genetic basis of pear-shaped tomato fruit," Theoretical and Applied Genetics, vol. 99, no. 5, pp. 844-850, 1999.

[26] B. Cong, L. S. Barrero, and S. D. Tanksley, "Regulatory change in YABBY-like transcription factor led to evolution of extreme fruit size during tomato domestication," Nature Genetics, vol. 40, no. 6, pp. 800-804, 2008.

[27] S. Muños, N. Ranc, E. Botton et al., "Increase in tomato locule number is controlled by two single-nucleotide polymorphisms located near WUSCHEL," Plant Physiology, vol. 156, no. 4, pp. 2244-2254, 2011.

[28] C. M. Rick and M. Holle, "Andean lycopersicon esculentum var. cerasiforme: genetic variation and its evolutionary significance," Economic Botany, vol. 44, no. 3, pp. 69-78, 1990.

[29] I. E. Peralta and D. Spooner, "History, origin and early cultivation of tomato (Solanaceae)," in Genetic improvement of Solanaceous crops, M. K. Razdan and A. K. Mattoo, Eds., vol. 2, pp. 1-24, Science Publisher, Enfield (NH), 2007. 
[30] R. G. Gardner and D. R. Panthee, "Grape tomato breeding lines: NC 1 grape, NC 2 grape, and NC 3 grape," HortScience, vol. 45, no. 12, pp. 1887-1888, 2010.

[31] J. H. Venema, P. Linger, A. W. Van Heusden, P. R. Van Hasselt, and W. Brüggemann, "The inheritance of chilling tolerance in tomato (Lycopersiconspp.)," The Journal of Plant Biology, vol. 7, no. 2, pp. 118-130, 2005.

[32] J. McGillivray and L. Clemente, "Effect of tomato size on solids content," in Proceedings of American Society of Horticultural Science, pp. 68-466, 1956.

[33] "North Carolina Agricultural Research Service. 1990. Notice of release of NC 84173 tomato line," https://mountainhort.ces.ncsu .edu/wp-content/uploads/2017/03/release-NC84173.pdf?fwd=no.

[34] K. Bhattarai, F. J. Louws, J. D. Williamson, and D. R. Panthee, "Resistance to Xanthomonas perforans race T4 causing bacterial spot in tomato breeding lines," Plant Pathology, vol. 66, no. 7, pp. 1103-1109, 2017.

[35] K. Bhattarai, F. J. Louws, J. D. Williamson, and D. R. Panthee, "Differential response of tomato genotypes to Xanthomonasspecific pathogen-Associated molecular patterns and correlation with bacterial spot (Xanthomonas perforans) resistance," Horticulture Research, vol. 3, Article ID 16035, 2016.

[36] J. W. Scott and R. G. Gardner, "Breeding for resistance to fungal pathogens," Genetic improvement of Solanaceous crops, vol. 2, pp. 421-456, 2006.

[37] K. Bhattarai, F. J. Louws, J. D. Williamson, and D. R. Panthee, "Diversity analysis of tomato genotypes based on morphological traits with commercial breeding significance for fresh market production in eastern USA," Australian Journal of Crop Science, vol. 10, no. 8, pp. 1098-1103, 2016.

[38] K. Bhattarai, Screening for Bacterial Spot (Xanthomonas spp.) Resistance in Tomato (Solanum lycopersicum L.) and Microbe Associated Molecular Patterns. Masters Thesis [Master thesis], North Carolina State University, 2016, https://repository.lib .ncsu.edu/bitstream/handle/1840.16/9920/etd.pdf;sequence=2 . 


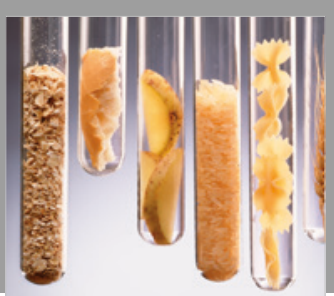

International Journal of Food Science

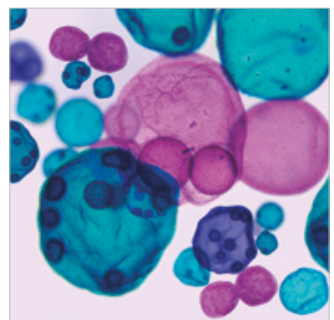

International Journal of Microbiology
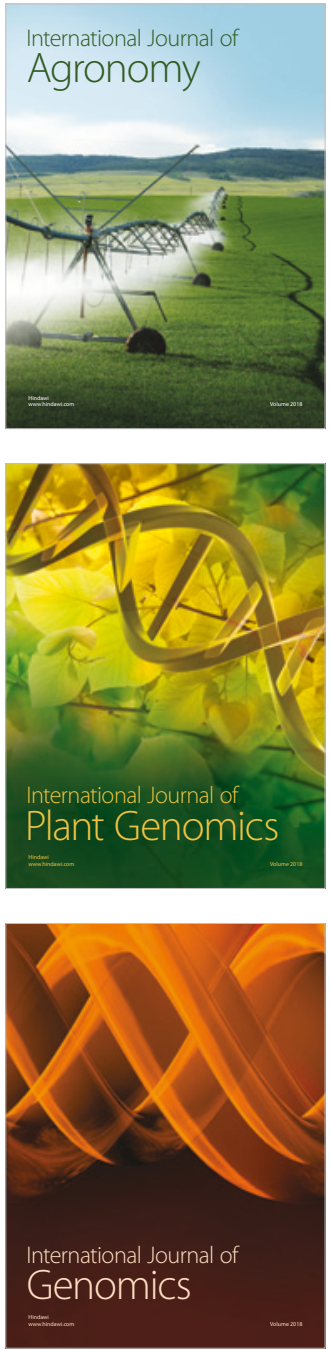

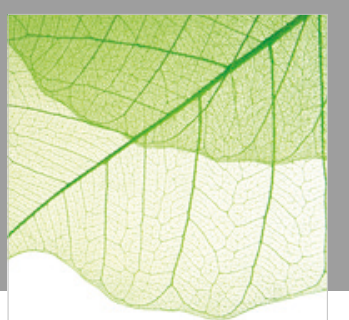

Journal of Botany
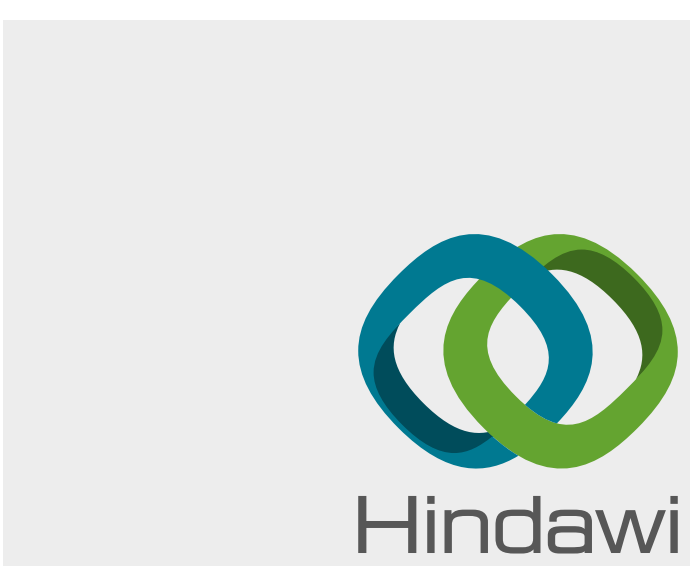

Submit your manuscripts at

www.hindawi.com
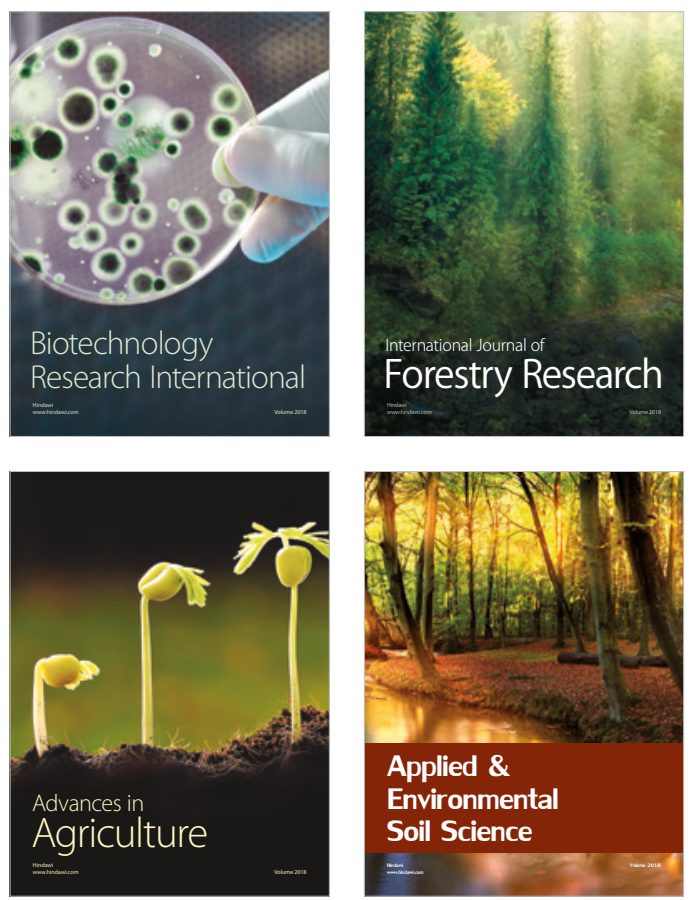

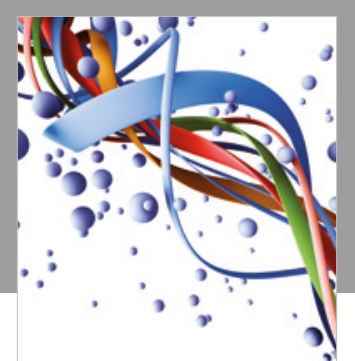

Scientifica

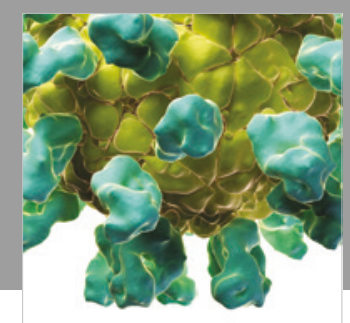

Veterinary Medicine International

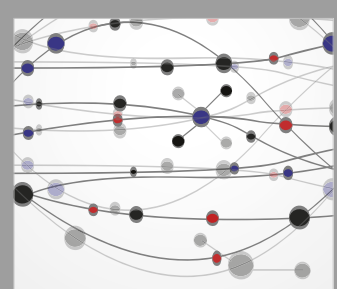

The Scientific World Journal
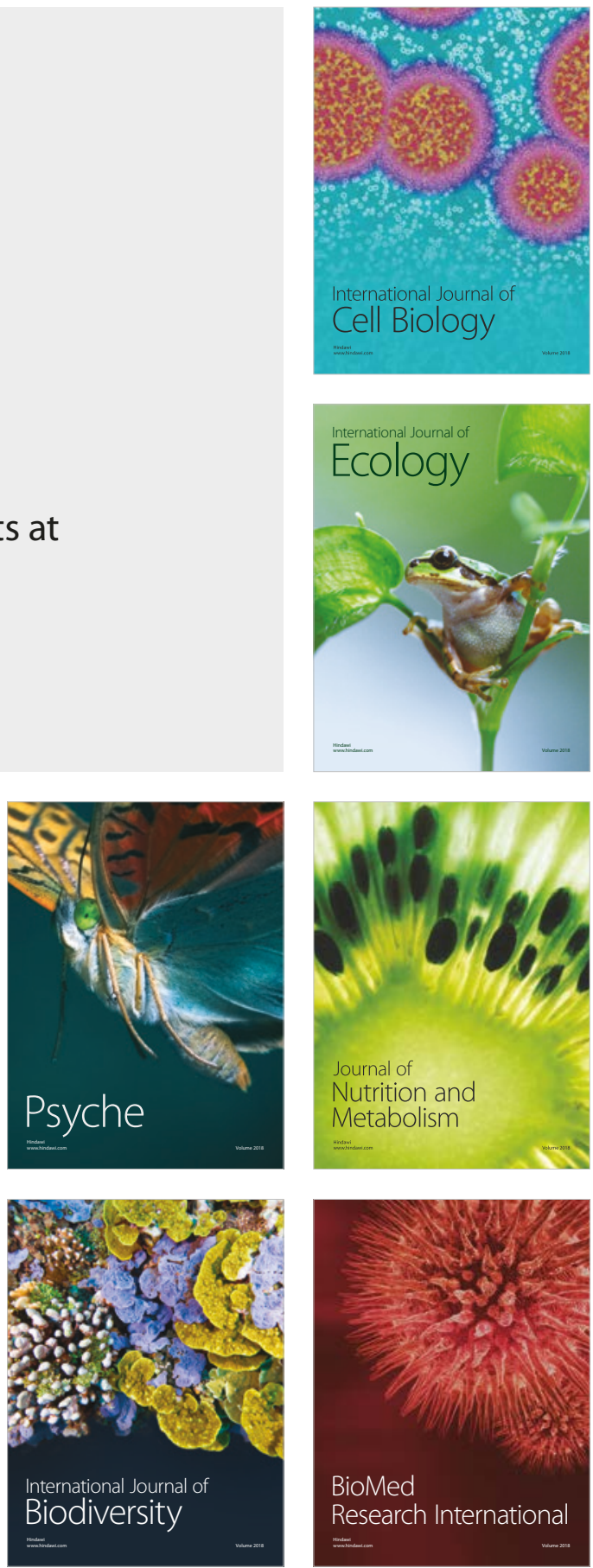